\title{
Wernicke-Korsakoff Syndrome
}

National Cancer Institute

\section{Source}

National Cancer Institute. Wernicke-Korsakoff Syndrome. NCI Thesaurus. Code C35764.

A syndrome caused by thiamine deficiency. It usually occurs in alcoholics and is

characterized by confusion, ataxia, and ophthalmoplegia. 